\title{
Successful anesthetic management of a partial lung resection for left pneumothorax with a severe, post-right upper middle lobectomy for chronic obstructive pulmonary disease
}

\author{
N.Fujii, M.Takada, H.Yamamoto
}

Department of anesthesiology, Tokyo Metropolitan Tama Medical Center, Tokyo, Japan

\section{Background}

Anesthetic management during thoracic surgery in patients with severe chronic obstructive pulmonary disease(COPD) who have undergone a lobectomy of the opposite lung can be challenging. We experienced a case of a patient who underwent an urgent left partial lung resection for pneumothorax using video-assisted thoracic surgery (VATS) under general anesthesia.

\section{Case}

\section{【History】}

69-year-old male Height: $167 \mathrm{~cm}$; Weight: $58.4 \mathrm{~kg}$ Sudden dyspnea due to left pneumothorax. Conservative therapy failed to repair the persistent air leak, and subcutaneous emphysema extended throughout his body. A partial resection of the left lung with VATS was planned.

【Past history】

22 49 y.0.: Smoked 40 cigarettes a day

49 y.o.: $\quad$ Gastorectomy

58 y.o.: $\quad$ COPD

62 y.o.: Right lung middle and lower lobectomy

66 y.o.: $\quad$ COPD on home oxygen

Problem therapy

\section{【Vital signs】}

HR 118bpm, BP 105/77mmHg,

SpO2 80 90\%(nasal high flow 40L $50 \%$ ), RR 28 regular

【Lab data (nasal high flow 40L 50\%)】 $\mathrm{pH} 7.42, \mathrm{PaO} 275.2 \mathrm{mmHg}, \mathrm{PaCO}_{2}$ $36.5 \mathrm{mmHg}, \mathrm{HCO}-23.4 \mathrm{mmol} / \mathrm{L}$ $\mathrm{BE}-0.2 \mathrm{mmol} / \mathrm{L}$, Lac $1.3 \mathrm{mnol} / \mathrm{L}$, $\mathrm{Hb} 11.0 \mathrm{~g} / \mathrm{dl}$

【ECG】

Sinus rhythm, HR 131bpm, IRBBB 【Spirometry】

(Done at 62 years old before lung resection)

VC $4.25 \mathrm{~L}, \%$ VC $123.9 \%$

FEV $1.02 .35 \mathrm{~L}$, FEV $1.0 \% 55.3 \%$

【Medications】

- Budesonide/Formoterol

Fumarate hydrate

- Tiotropium bromide hydrate

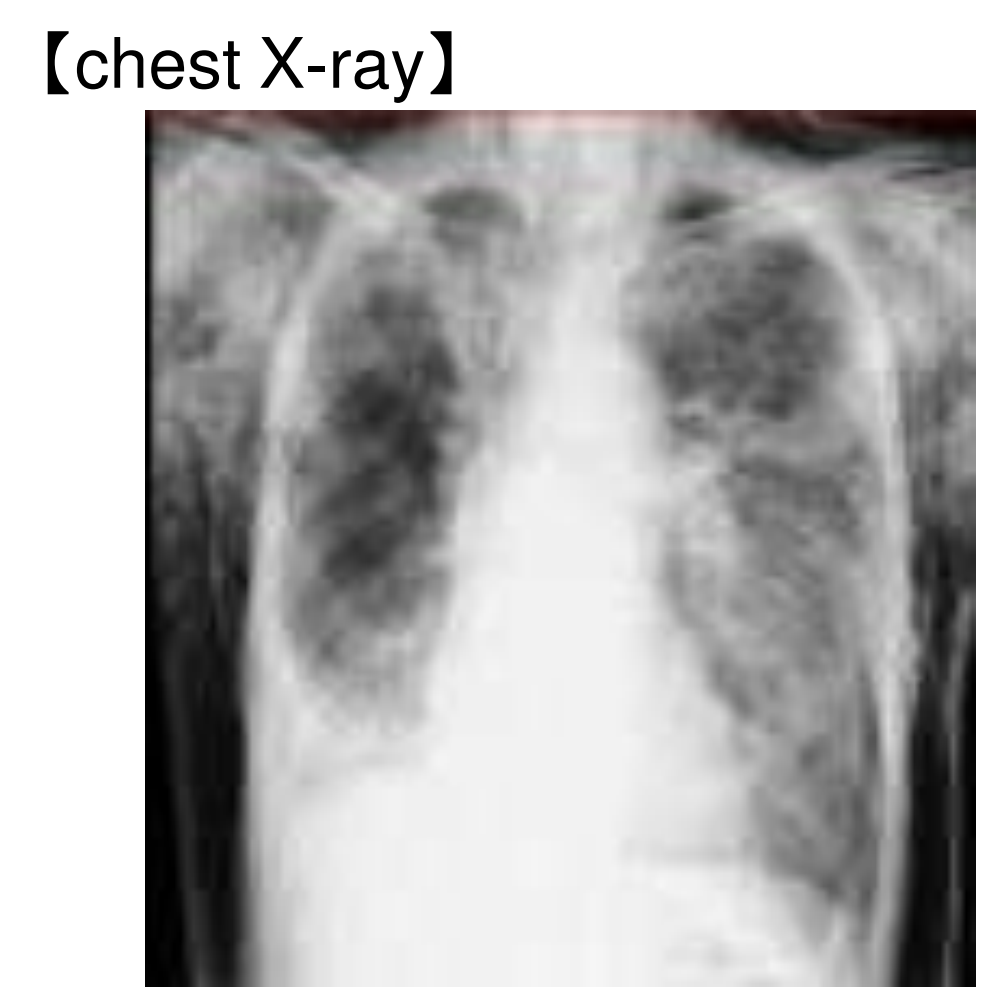

【CT】
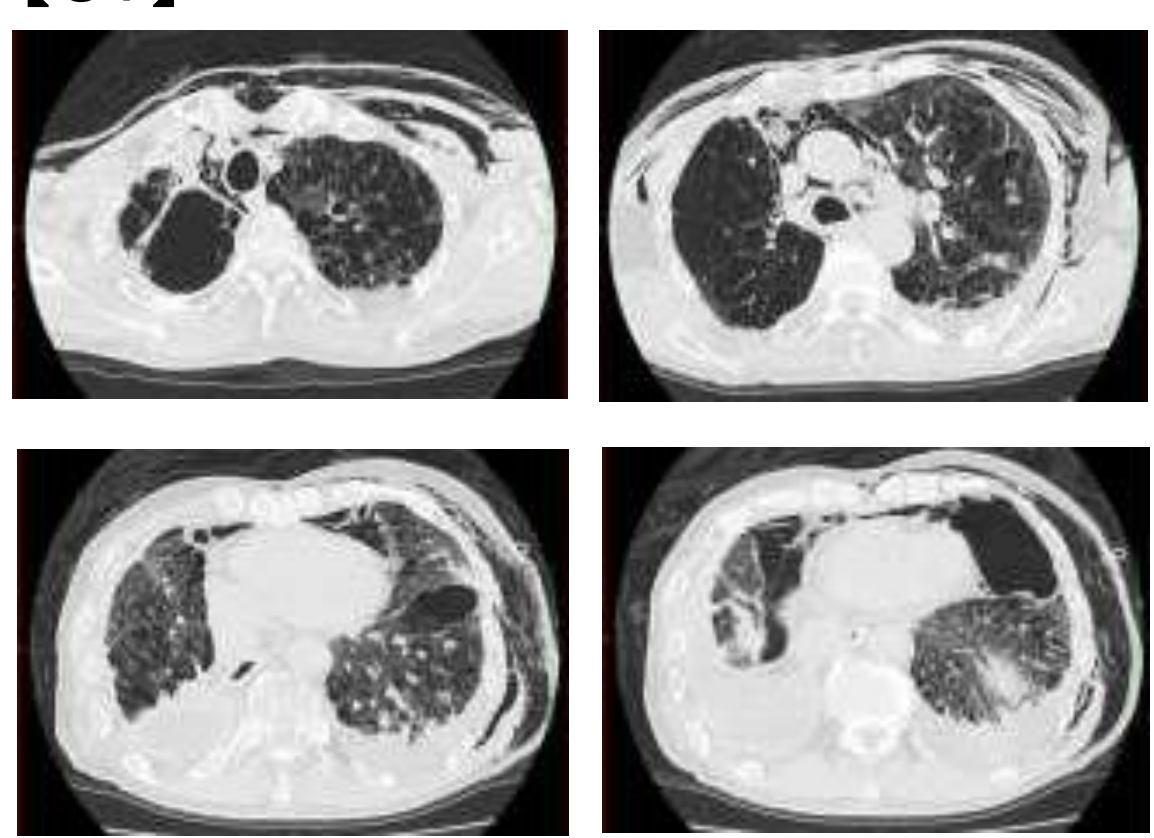

\#1 Severe COPD after lung resection

\#2 Due to lung surgery, one lung ventilation was required

\section{Discussion}

\section{\#1 Severe respiratory disease and anesthesia}

Severe respiratory diseases are a high risk factor of postoperative pulmonary complications (PPC). Pulmonary factors alone cannot predict PPC but can do so in combination with non-pulmonary factors. In this patient, we finally decided on surgery because his respiratory condition recovered to the predyspnea state. The patient gave his informed consent for the operation.

\#2 The anesthesia options:

(1) General anesthesia and positive pressure ventilation ( \pm one lung ventilation)

(2) Epidural anesthesia with non-positive pressure ventilation or spontaneous breathing

(3) General anesthesia with extracorporeal membrane oxygenation.

\section{Management}

Our choice (1). Total intravenous anesthesia was given, and intubation was done with a single tube and bronchial blocker. Mask ventilation (MV) and intubation were difficult due to the subcutaneous emphysema. The oral airway and two-handed MV method improved the MV, and Airwayscope ${ }^{\mathrm{TM}}$ facilitated intubation. 100\% oxygen with bilateral ventilation was maintained during surgery. Once during surgery a spark from the electric scalpel briefly ignited the oxygen which filled his thoracic cavity. Fortunately the lesion was large and easily identified. Then ventilation was stopped, while the lung was resected. After full reversal of the muscle relaxant, he was extubated. His $\mathrm{PaO}_{2}$ was $72.6 \mathrm{mmHg}$ and his $\mathrm{PaCO}_{2} 40.2 \mathrm{mmHg}$ under spontaneous breathing on $6 \mathrm{~L}$ mask. The anesthesia time was $157 \mathrm{~min}$, and the operation time was $41 \mathrm{~min}$. He was discharged on postoperative day 12 day.

\section{Conclusion}

Anesthetic management of severe COPD has a high risk of PPC. As there are no clear criteria for anesthetic management, the risks and benefits of surgery and anesthesia should be discussed carefully for each case . 